\title{
Increased endostatin/collagen XVIII expression correlates with elevated VEGF level and poor prognosis in hepatocellular carcinoma
}

Tsung-Hui $\mathrm{Hu}^{1, *}$, Chao-Cheng Huang,** Chia-Ling $\mathrm{Wu}^{3}$, Pey-Ru Lin ${ }^{4}$, Shang-Yun Liu ${ }^{2}$, Jui-Wei Lin ${ }^{2}$, Jiin-Haur Chuang ${ }^{3}$ and Ming Hong Tai ${ }^{4,5}$

${ }^{1}$ Division of Hepatology, Kaohsiung Chang Gung Memorial Hospital, Kaohsiung, Taiwan; ${ }^{2}$ Division of Pathology, Kaohsiung Chang Gung Memorial Hospital, Kaohsiung, Taiwan; ${ }^{3}$ Department of Surgery, Kaohsiung Chang Gung Memorial Hospital, Kaohsiung, Taiwan; ${ }^{4}$ Department of Medical Education and Research, Kaohsiung Veterans General Hospital, Kaohsiung, Taiwan and ${ }^{5}$ Department of Biological Sciences, National Sun Yat-Sen University, Kaohsiung, Taiwan

\begin{abstract}
Liver is the primary source for collagen XVIII, the precursor of angiogenesis inhibitor, endostatin. However, the role of endostatin/collagen XVIII expression during liver carcinogenesis remains elusive. Therefore, we studied its expression in five hepatoma cell lines and 105 hepatocellular carcinoma specimens. The poorly differentiated hepatoma cell lines exhibited increased endostatin/collagen XVIII levels compared with the well-differentiated ones. In hepatoma tissues, endostatin/collagen XVIII expression was detected in various types of liver cells and was significantly stronger in adjacent nontumor tissues than that in tumors $(\boldsymbol{P}<0.001)$. Endostatin/collagen XVIII expression in nontumor tissues correlated with tumor stages $(P=0.014)$ and expression of vascular endothelial growth factor $(P=0.007)$, but not the stages of hepatic fibrosis $(P>0.05)$. Kaplan-Meier analysis showed that patients with higher endostatin/collagen XVIII expression had significantly shorter overall survival $(P=\mathbf{0 . 0 1 1})$ and disease-free survival $(P=\mathbf{0 . 0 0 3 4})$. Moreover, endostatin/collagen XVIII level was an independent prognostic factor for tumor recurrence $(P=0.034)$ by multivariate analysis. In conclusion, increased endostatin/collagen XVIII expression correlated with hepatoma progression and predicted poor prognosis for patients with hepatocellular carcinoma.

Modern Pathology (2005) 18, 663-672, advance online publication, 17 December 2004; doi:10.1038/modpathol.3800336
\end{abstract}

Keywords: endostatin; collagen XVIII; VEGF; hepatocellular carcinoma; prognosis

Hepatocellular carcinoma (HCC) is extensively vascularized and the occurrence of primary intrahepatic and lung metastases suggests its mainly hematogenous dissemination. Thus, angiogenesis plays a pivotal role during hepatic carcinogenesis. Angiogenesis may be the net result of a balance between the positive and negative regulators of neovascularization. Several angiogenic factors participated in HCC progression, including vascular endothelial growth factor (VEGF),${ }^{1-3}$ transformation

Correspondence: Dr M-H Tai, PhD, Department of Medical Education and Research, Kaohsiung Veterans General Hospital, 386 Ta-Chung 1st Road, Kaohsiung 813, Taiwan.

E-mail: mhtai@isca.vghks.gov.tw

* These authors equally contributed to this work.

Received 23 June 2004; revised and accepted 8 October 2004; published online 17 December 2004 growth factor- $\alpha$ (TGF- $\alpha),{ }^{4}$ insulin-like growth factor (IGF-II), ${ }^{5}$ and hepatocyte growth factor. ${ }^{6}$ However, liver is also a rich source for the precursors of many endogenous angiogenesis inhibitors such as thrombospondin, ${ }^{7}$ angiostatin, ${ }^{8}$ and endostatin. ${ }^{9}$ Among these inhibitors, endostatin, a $20-\mathrm{kDa}$ protein derived from carboxy (C)-terminal proteolytic fragment of collagen XVIII (C18), has attracted tremendous attention since its discovery because of its potency to inhibit neovascularization and tumor growth without inducing drug resistance in mice. ${ }^{10,11}$

The role of endostatin/C18 expression during liver cirrhosis or HCC progression remains controversial despite previous studies. ${ }^{12-15}$ In the present study, we analyzed endostatin/C18 expression in HCC cell lines as well as clinical specimens, thereby to delineate the involvement of endostatin/C18 expression in liver carcinogenesis. 


\section{Materials and methods}

\section{Characterization of Endostatin Antibodies}

The endostatin complementary DNA (cDNA) was cloned by reverse transcription-polymerase chain reaction (RT-PCR) as previously described and confirmed by sequencing analysis. ${ }^{16}$ The endostatin cDNA was subcloned into pET15b vector (Novagen Inc., Madison, WI, USA) and was transformed into BL-21 cells (DE3, pLysS; Novagen Inc.) for expression. The 6xHis-tagged endostatin was purified from induced bacteria cells by Ni-NTA-agarose (Qiagen, $\mathrm{GmbH}$, Germany) and desalted by G25 Sephadex column (Amersham Pharmacia Biotech, UK). The endostatin antibodies were raised by periodic injection of endostatin into rabbits. The serum was collected from immunized rabbits and characterized prior to studies.

\section{Cell Cultures and Transfection}

Human hepatoma Chang liver, Hep3B, J5, Mahlavu, SK-Hep-1 cells, and Hela cells were cultured in DMEM media (Life Technologies, Rockville, $\mathrm{MD}$, USA) in $5 \% \mathrm{CO}_{2}$ incubator. For expression in mammalian cells, endostatin cDNA was subcloned into pSecTagB vector (Invitrogen Life Technologies; Carlsbad, CA, USA), and transfected into Hela cells $\left(1 \times 10^{6}\right.$ cells in six-well plate) using Lipofectamine (Invitrogen Life Technologies) following the protocol of the manufacturer.

\section{Protein Extraction and Western Blot Analysis}

Protein extracts were prepared from Mahlavu cells using stepwise extraction procedures as previously described: ${ }^{17}$ (1) EDTA extraction with solution containing $10 \mathrm{mM}$ EDTA, $1 \mathrm{mM}$ PMSF, $1 \mu \mathrm{g} /$ $\mathrm{ml}$ aprotinin, $1 \mu \mathrm{g} / \mathrm{ml}$ leupeptin, $1 \mu \mathrm{g} / \mathrm{ml}$ pepstatin; (2) detergent buffer containing $50 \mathrm{mM}$ Tris-HCl, $\mathrm{pH} 7.4,1 \% \mathrm{NP}-40,0.25 \%$ sodium deoxycholate, $150 \mathrm{mM} \mathrm{NaCl}, 1 \mathrm{mM}$ PMSF, $1 \mu \mathrm{g} / \mathrm{ml}$ aprotinin, $1 \mu \mathrm{g} /$ $\mathrm{ml}$ leupeptin, and $1 \mu \mathrm{g} / \mathrm{ml}$ pepstatin; (3) urea extraction using $8 \mathrm{M}$ urea. The concentration of protein extracts was determined by Bradford assay. In all, $30 \mu \mathrm{g}$ of protein was subjected to separation by SDS-PAGE and transferred onto polyvinylidene difluoride membranes (Immobilon-P, Millipore). The filter was blocked with $5 \%$ nonfat dry milk in TBST buffer containing $10 \mathrm{mM}$ Tris, pH 7.5, $100 \mathrm{mM} \mathrm{NaCl}$, and $0.1 \%$ Tween-20. Afterward, the filter was incubated with endostatin antibodies (1:500) for $1 \mathrm{~h}$, then incubated with goat-anti-rabbit antibodies conjugated with horseradish peroxidase (1:2500 dilution) for $30 \mathrm{~min}$ and detected with chemiluminescence ECL kit (Amersham Pharmacia Biotech, UK).

\section{Immunofluorescence}

Hepatoma cells were plated on glass coverslips in a 24 -well plate $\left(1 \times 10^{4}\right.$ cells per well), fixed with $4 \%$ paraformaldehyde, permeabilized with $0.5 \%$ Triton $\mathrm{X}-100$, and incubated with endostatin antibodies (1:100) for $1 \mathrm{~h}$. Subsequently, cells were probed with FITC-conjugated secondary antibodies (1:2500; Molecular Probe; Eugene, OR, USA) for $30 \mathrm{~min}$. The nucleus was stained by propidium iodide $(1 \mu \mathrm{g} / \mathrm{ml}$; Molecular Probe) as red fluorescence under a fluorescence microscope.

\section{qRT-PCR}

RNA was isolated from hepatoma cells or 10 HCC specimens with paired tumor and nontumor tissues using RNAzol (TEL-TEST Inc., Friendswoods, TX, USA). For reverse transcription, $5 \mu \mathrm{g}$ of total RNA was used for reverse transcription with Superscriptase II (Life Technologies) using olio-dT and random primers. One twentieth of reverse-transcription products was used as template for real-time PCR in ABI Prism 7700 sequence detector (Applied Biosystems) using a SYBR green assay. PCR reaction was performed and the amplification and detection were performed by: 1 cycle of $95^{\circ} \mathrm{C}$ for $10 \mathrm{~min}, 40$ cycles of $95^{\circ} \mathrm{C}$ for $15 \mathrm{~s}$, and $62^{\circ} \mathrm{C}$ for $20 \mathrm{~s}$, and $72^{\circ} \mathrm{C}$ for $15 \mathrm{~s}$. After completion, a final melting curve was performed by denaturation at $95^{\circ} \mathrm{C}$ for $15 \mathrm{~s}$ and then was recorded by cooling to $60^{\circ} \mathrm{C}$ and then heating slowly until $95^{\circ} \mathrm{C}$ for $20 \mathrm{~min}$ according to the dissociation protocol of the ABI7700 instrument. The primer sequences for endostatin/C18 were: forward primer $5^{\prime}$-gtgcccatcgtcaacctca-3', reverse primer $5^{\prime}$-aaggagaagatgcgtgccc- $3^{\prime}$, which amplified a 104-bp C18 cDNA fragment.

\section{Enzyme Immunoassay}

The endostatin levels in cultured media of hepatoma cells were determined by endostatin EIA kit (Accucyte, Cytimmune Science Inc., Ml, USA) following the manufacturer's instructions. The endostatin concentration was measured and expressed as mean \pm s.e.m. from triplicate data.

\section{HCC Specimens}

A total of 105 surgically resected HCC specimens were collected at the Kaohsiung Chang Gung Memorial Hospital from January 1986 to December 1997 as previously described. ${ }^{18}$ The closing date of follow-up was December 31, 2002. All the HCC specimens consisted of paired tumor and adjacent nontumor parts. The histological grades of HCC were divided into three groups based on the Edmondson-Steiner classification. The stages of HCC were classified according to the staging system by the International Union against Cancer with 
slight modification as described previously. ${ }^{18}$ The hepatic fibrosis stages in nontumor tissues were determined by masson trichrome staining and divided into three groups for comparison: group 1 (fibrosis 0-1), group 2 (fibrosis 2-3), and group 3 (fibrosis 4: cirrhosis).

\section{Immunohistochemistry and Scoring}

The paraffin-embedded tissue blocks were sectioned into $4 \mu \mathrm{m}$ slices and mounted on the poly-L-lysinecoated slides. After deparaffinization, the slides were blocked with $3 \%$ hydrogen peroxide for $10 \mathrm{~min}$ and subjected to antigen retrieval with microwave in $10 \mathrm{mM}$ citrate buffer for $15 \mathrm{~min}$. The endostatin antibodies (1:100 dilution) or VEGF antibodies (1:250; Santa Cruz; Santa Cruz, CA, USA) were applied onto the sections and incubated at room temperature for $30 \mathrm{~min}$ followed by repeated wash with phosphate-buffered saline (PBS). Horseradish peroxidase/Fab polymer conjugate (Polymer detection system, Zymed, USA) was then applied to the sections and the sections were incubated for $30 \mathrm{~min}$. After rinsing with PBS, the sections were incubated with peroxidase substrate diaminobenzidine (1:20 dilution, Zymed) for $5 \mathrm{~min}$. Thereafter, the sections were counterstained with Gill's hematoxylin for $2 \mathrm{~s}$, dehydrated with serial ethyl alcohol, cleared with xylene, and finally mounted. The preimmune serum (1:100 dilution) from the rabbits was used as negative control of immunohistochemistry.

The labeling index for the intensity of C18 derivatives and VEGF staining was evaluated by two independent pathologists as 1, weak; 2, intermediate; 3 , strong using normal hepatocytes as internal control. From an individual with traumatic internal bleeding, the putative normal liver tissue was collected by partial hepatectomy and used as a positive control for C18 staining with score 2 (data not shown). A stronger staining intensity than the positive control was defined as score 3 and a weaker staining was defined as score 1.

\section{Statistical Methods}

Comparisons between groups of related samples were assessed by the Wilcoxon paired-sample test. Comparisons between groups of independent samples were assessed by the Student's $t$-test, one-way ANOVA, the Mann-Whitney $U$-test or the Kruskal-Wallis test. The associations between categorical variables were assessed using the $\chi^{2}$ test or Fisher's exact test. The correlation between continuous variables was determined by Spearman's rank correlation test. Survival rates were calculated by the Kaplan-Meier methods and the difference in survival was compared with the log rank test. The influence of various features on overall or disease-free survival was assessed by the Cox's proportional hazard model. A $P$-value of less than 0.05 was considered statistically significant.

\section{Results}

\section{Detection of Endostatin/C18 in Hepatoma Cells}

Recombinant endostatin was purified to near homogeneity for generation of endostatin antibodies (Figure 1a), which specifically detected a $20-\mathrm{kDa}$ protein in cells transfected with endostatin expression plasmid but not vector or control (Figure 1b). It was reported that endostatin and the proteolytic fragments of C18 could be extracted using various extraction agents. ${ }^{18} \mathrm{We}$ evaluated the specificity of endostatin antibodies by Western blot analysis using various extracts of hepatoma cells. In EDTA extract, endostatin antibodies specifically detected a $20-\mathrm{kDa}$ protein (Figure 1c), which had a molecular weight approximate to that of endostatin. Following subsequent detergent extraction, a $30-\mathrm{kDa}$ protein, close to the size of NC1 domain, was identified (Figure 1c). In urea extract, several proteins of a size larger than $200 \mathrm{kDa}$, similar to that of $\mathrm{C} 18$, were detected (Figure 1c). These distinct protein bands could be effectively abrogated when absorbed into the antibodies with excess amount of endostatin (data not shown). In histological analysis, the immunostaining of endostatin antibodies was mainly localized in the cytoplasm of hepatocytes of liver tissues (Figure 3), whereas the preimmune antibodies showed no detectable staining (data not shown). These results validated the specificity of endostatin antibodies for C18, and its proteolytic derivatives including endostatin in hepatoma cells thereby warranted their use in the subsequent histological studies. As endostatin antibodies did not differentiate endostatin from other C18 derivatives, the immunostaining in this study was considered to reflect the overall endostatin/C18 levels in tissues.

\section{Increased Endostatin/C18 Expression in Poorly Differentiated Hepatoma Cells}

The endostatin/C18 expression level was investigated in five hepatoma cell lines. The endostatin/ C18 mRNA levels were significantly elevated in poorly differentiated hepatoma cells such as Mahlavu and SK-Hep-1 cells compared with the well-differentiated Chang liver or Hep3B cells (Figure 2a). Besides, the endostatin release in the cultured media of poorly differentiated hepatoma cells was higher than the well-differentiated ones (Figure 2b). Immunofluorescence analysis also revealed stronger endostatin/C18 staining in poorly differentiated Mahlavu cells (Figure 2c). 
a

b

$\mathrm{kDa}$ 总

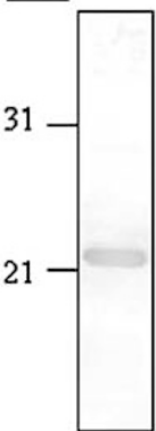

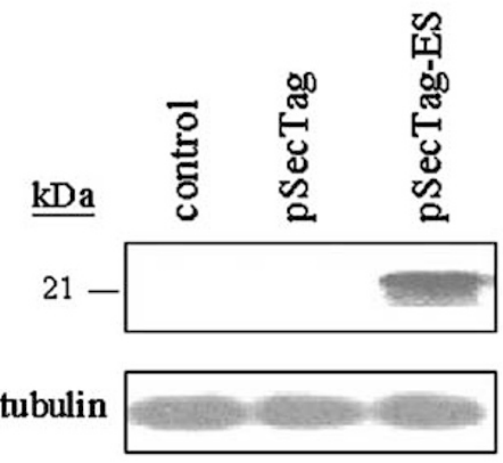

C

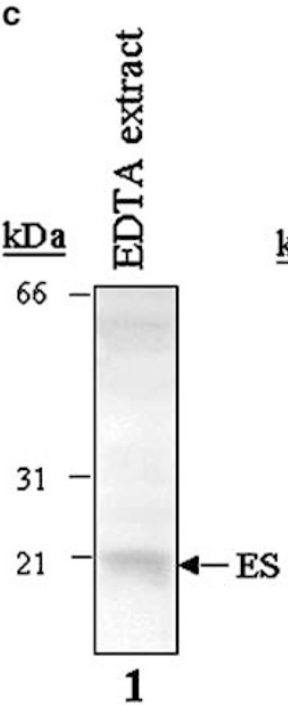

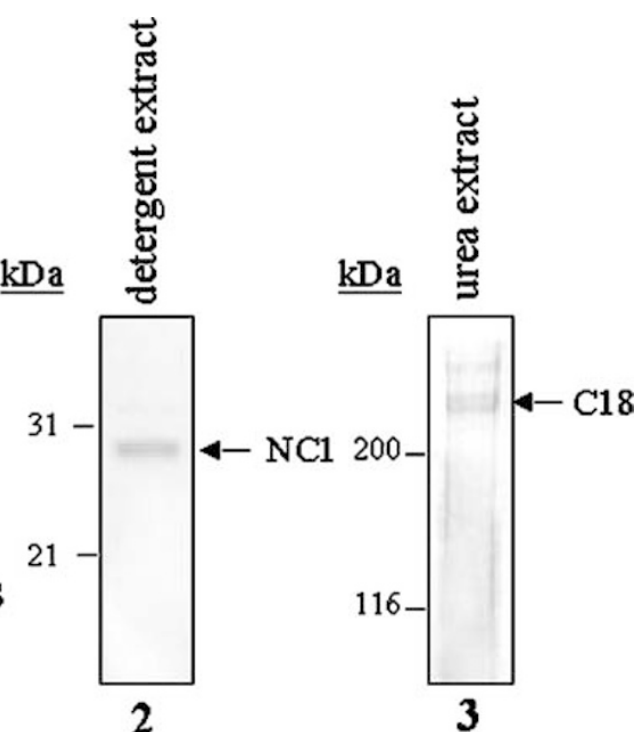

Figure 1 Characterization of endostatin antibodies. (a) Purification of recombinant endostatin. The purity of endostatin (2 $\mu \mathrm{g})$ was analyzed by $12.5 \%$ SDS-PAGE analysis. (b) Western blot analysis of endostatin expression in transfected Hela cells. After transfection for $48 \mathrm{~h}$, Hela cells were harvested for Western blot analysis using endostatin antibodies (1:500 dilution), which specifically detected endostatin only in cells transfected with endostatin-expressing vector, pSecTagB-ES, but not pSecTagB. (c) Detection of C18 and its proteolytic fragments in Mahlavu cells by Western blot using endostatin antibodies. Lane 1: endostatin (ES; $\sim 20 \mathrm{kDa}$ as indicated by arrow) in EDTA extract of Mahlavu cells (12.5\% SDS-PAGE); lane 2: NC1 domain ( $\sim 30 \mathrm{kDa}$; indicated by arrow) in detergent extract of Mahlavu cells (10\% SDS-PAGE); lane 3: C18 ( 200 kDa; indicated by arrow) in urea extract of Mahlavu cells (6\% SDS-PAGE).

a
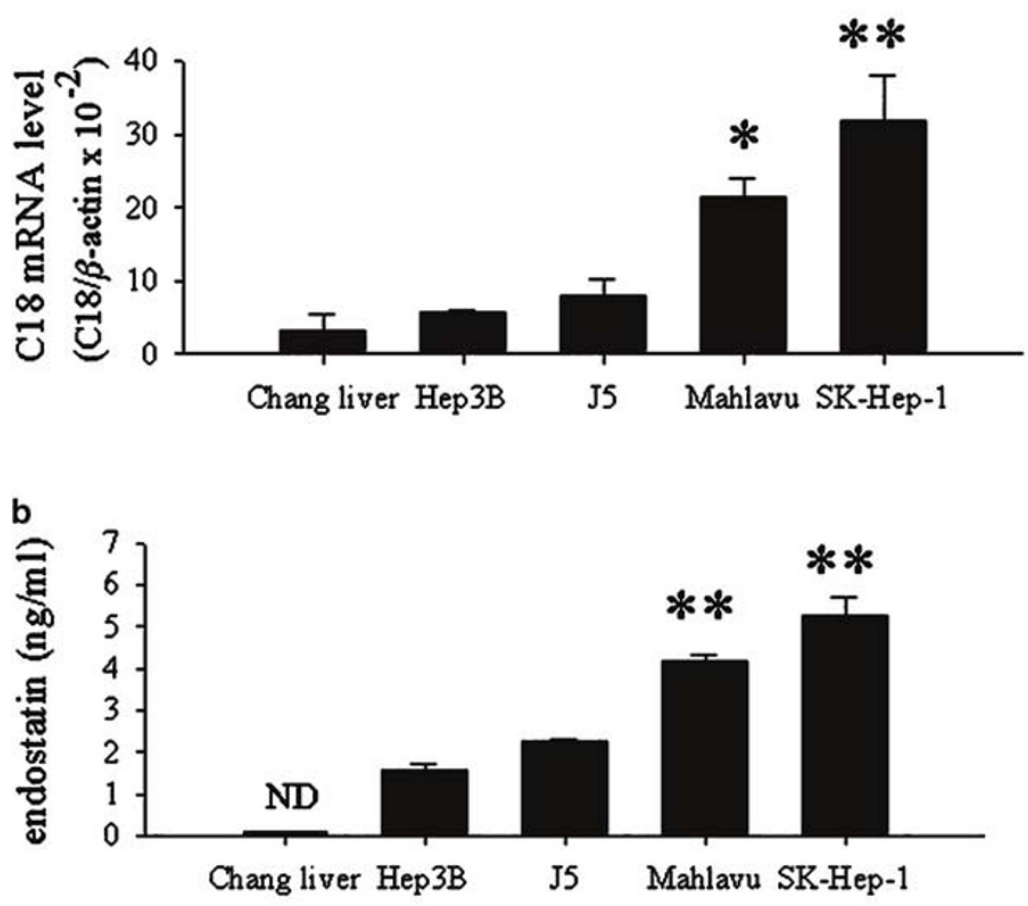

C
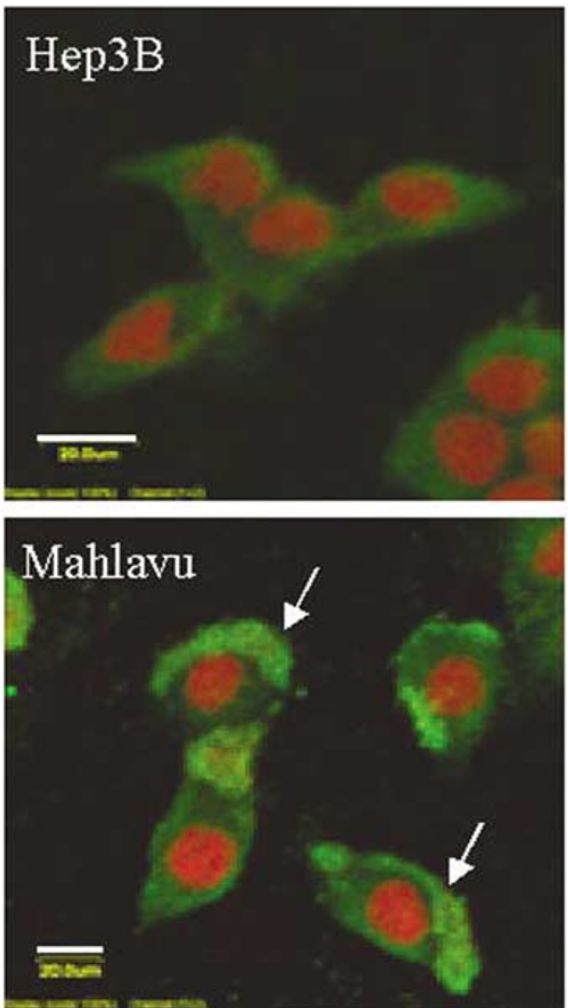

Figure 2 Expression of endostatin/C18 in hepatoma cell lines. (a) RT-PCR analysis of the endostatin/C18 mRNA levels in hepatoma cell lines. The endostatin/C18 mRNA levels were quantified and expressed as qRT-PCR ratio vs $\beta$-actin $\left(\times 10^{-2}\right)$ from triplicate data. ${ }^{*} P<0.05$; ${ }^{*} P<0.001$. (b) EIA analysis of endostatin secretion in hepatoma cells. The endostatin levels in cultured media from $1 \times 10^{6}$ hepatoma cells were determined by EIA and expressed as mean \pm s.e.m. from triplicate data. (c) Immunofluorescence analysis of endostatin/C18 expression in Hep3B (top) and Mahlavu cell (bottom). Hepatoma cells were fixed, stained with endostatin antibodies (1:100), and detected with FITC-conjugated anti-rabbit secondary antibodies. The cell nucleus was visualized by staining with propidium iodide (red). Arrows indicated strong immunostaining of endostatin/C18 (green) in Mahlavu cells. The scale bar, $20 \mu \mathrm{m}$. 

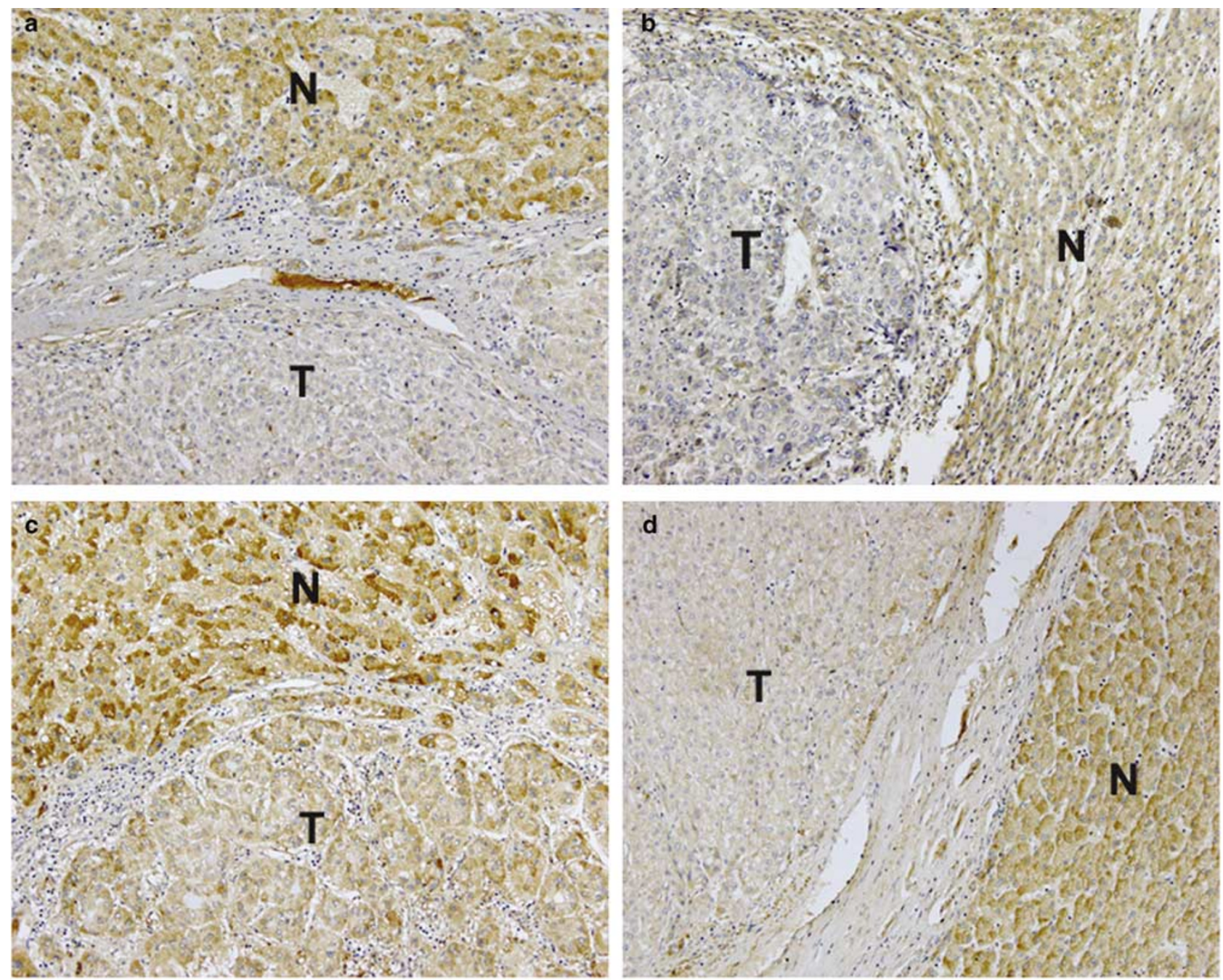

Figure 3 The differential expression of endostatin/C18 in HCC specimens. (a-d) The C18 expression in the tumor (T) and nontumor (N) tissues from four HCC cases was depicted. The photographs were taken at a magnification of $\times 100$ for $(\mathbf{a}, \mathbf{b})$ and $\times 200$ for $(\mathbf{c}, \mathbf{d})$. The intensities of C18 in nontumor tissues were higher than those in tumor tissues.

\section{Differential Endostatin/C18 Expression between Tumor and Nontumor Tissues in HCC}

Immunohistochemical studies were performed to analyze endostatin/C18 expression in 105 surgically resected HCC specimens. The immunoreactivities of endostatin/C18 were mainly localized in the pericellular matrix and cytoplasm of hepatocytes in tumors and nontumor tissues (Figure 3). Besides, endostatin/C18 immunostaining was found in sinusoidal endothelial cells, epithelial cells of bile duct, and newly formed blood vessels (supplementary data). These findings are consistent with previous reports. ${ }^{15,17,19}$

There was a differential endostatin/C18 expression in HCC specimens that endostatin/C18 immunostaining was stronger in the nontumor tissues than that in HCC $(P<0.001$; Figure 3$)$. Besides, endostatin/C18 expression in nontumor tissues was positively correlated with the tumor stages of HCC $(P=0.014$; Table 1$)$ but not the hepatic fibrosis stages or necroinflammatory grades of HCC specimens $(P>0.05$; Table 1).

\section{Correlation between Endostatin/C18 and VEGF Expression in HCC}

The increased endostatin/C18 expression may modulate the angiogenic states of hepatoma. Thus, we analyzed the expression of angiogenic factor, VEGF, as an index for angiogenic states in HCC specimens. VEGF immunostaining was more prominent in hepatocytes of the nontumor tissues than that in the tumors (Figure 4), which was similar to that of endostatin/C18. Besides, tissue VEGF levels were strongly correlated with tumor stages $(P=0.001)$. Above all, there was a significant correlation 
Table 1 Correlation between endostatin/C18 expression in nontumor tissues and clinicopathological parameters of HCCs

\begin{tabular}{|c|c|c|c|c|}
\hline \multirow[t]{2}{*}{ Variables } & \multicolumn{3}{|c|}{ Scores of endostatin/C18 in nontumor tissues } & \multirow[t]{2}{*}{$\mathrm{P}$} \\
\hline & $1(\mathrm{n}=36)$ & $2(\mathrm{n}=50)$ & $3(\mathrm{n}=19)$ & \\
\hline Sex & & & & NS $(0.104)^{\mathrm{a}}$ \\
\hline Male $(n=84)$ & 25 & 44 & 15 & \\
\hline Female $(n=21)$ & 11 & 6 & 4 & \\
\hline Hepatic fibrosis & & & & NS $(0.84)^{\mathrm{a}}$ \\
\hline Score $0-1(n=17)$ & 4 & 9 & 4 & \\
\hline Score $2-3(n=27)$ & 10 & 13 & 4 & \\
\hline Score $4(n=61)$ & 22 & 28 & 11 & \\
\hline HBsAg & & & & NS $(0.56)^{\mathrm{a}}$ \\
\hline Positive $(n=69)$ & 25 & 31 & 13 & \\
\hline Negative $(n=31)$ & 8 & 17 & 6 & \\
\hline$H C V A b$ & & & & NS $(0.76)^{\mathrm{a}}$ \\
\hline Positive $(n=29)$ & 8 & 15 & 6 & \\
\hline Negative $(n=71)$ & 25 & 33 & 13 & \\
\hline Tumor numbers & & & & NS $(0.109)^{\mathrm{a}}$ \\
\hline Solitary $(n=81)$ & 30 & 39 & 12 & \\
\hline Multiple $(n=24)$ & 6 & 11 & 7 & \\
\hline Grades* & & & & NS $(0.97)^{\mathrm{a}}$ \\
\hline Well $(n=26)$ & 8 & 13 & 5 & \\
\hline Moderate $(n=52)$ & 20 & 23 & 9 & \\
\hline Poor $(n=27)$ & 8 & 14 & 5 & \\
\hline Stages & & & & $0.014^{*, \mathrm{a}}$ \\
\hline $\mathrm{I}(n=16)$ & 8 & 7 & 1 & \\
\hline II $(n=33)$ & 12 & 17 & 4 & \\
\hline III $(n=33)$ & 9 & 17 & 7 & \\
\hline IV $(n=23)$ & 7 & 9 & 7 & \\
\hline Capsulation & & & & NS $(0.60)^{\mathrm{a}}$ \\
\hline With $(n=44)$ & 17 & 19 & 8 & \\
\hline Without $(n=61)$ & 19 & 31 & 11 & \\
\hline$V E G F$ & & & & $0.007^{*, \mathrm{a}}$ \\
\hline Score $1(n=21)$ & 8 & 11 & 2 & \\
\hline Score $2(n=54)$ & 23 & 25 & 6 & \\
\hline Score $3(n=30)$ & 5 & 14 & 11 & \\
\hline Age & $55.6 \pm 11.8$ & $55.2 \pm 12.9$ & $55.5 \pm 11.4$ & NS $(0.87)^{\mathrm{b}}$ \\
\hline Tumor sizes $(\mathrm{cm})$ & $6.1 \pm 3.9$ & $6.2 \pm 3.1$ & $6.8 \pm 4.2$ & NS $(0.76)^{\mathrm{b}}$ \\
\hline$\alpha-\mathrm{FP}(\mathrm{ng} / \mathrm{ml})$ & $2046 \pm 7343$ & $2776 \pm 10342$ & $3437 \pm 7800$ & NS $(0.84)^{\mathrm{c}}$ \\
\hline
\end{tabular}

$\alpha$-FP, alpha fetoprotein; HBsAg, hepatitis B surface antigen, HCV Ab, hepatitis C antibody; NS, not significant.

*According to the Edmondson and Steiner's classification.

Categorical data were compared by: a: $\chi^{2}$ test or Fisher's exact test, b: one-way ANOVA, c: Kruskal-Wallis test.

between endostatin/C18 and VEGF expression in nontumor $(P=0.007$; Table 1$)$ and tumor tissues $(P=0.01)$ (Figure 4).

\section{The Increased Endostatin/C18 Expression was Associated with Poor Prognosis of HCC Patients}

As tumor stage and angiogenic states are critical factors for the survival outcome and tumor recurrence, the relation between endostatin/C18 expression and the prognosis of HCC patients after surgery was investigated. Kaplan-Meier analysis revealed that HCC patients with increased endosta-
tin/C18 expression in nontumor tissues survived significantly shorter $(P=0.011$, Figure 5a) and had a higher incidence of recurrence $(P=0.0034$, Figure $5 b)$ after surgery. The endostatin/C18 levels in tumor tissues only offered predictive value to the diseasefree survival $(P=0.035)$, but not the overall survival of HCC patients.

The Labeling Index of Endostatin/C18 was a Prognostic Factor for Tumor Recurrence of HCC Patients

In Cox's hazard model, the endostatin/C18 levels in tumor and nontumor tissues were predictive factors 


\section{C18}

stage I

\section{stage II}
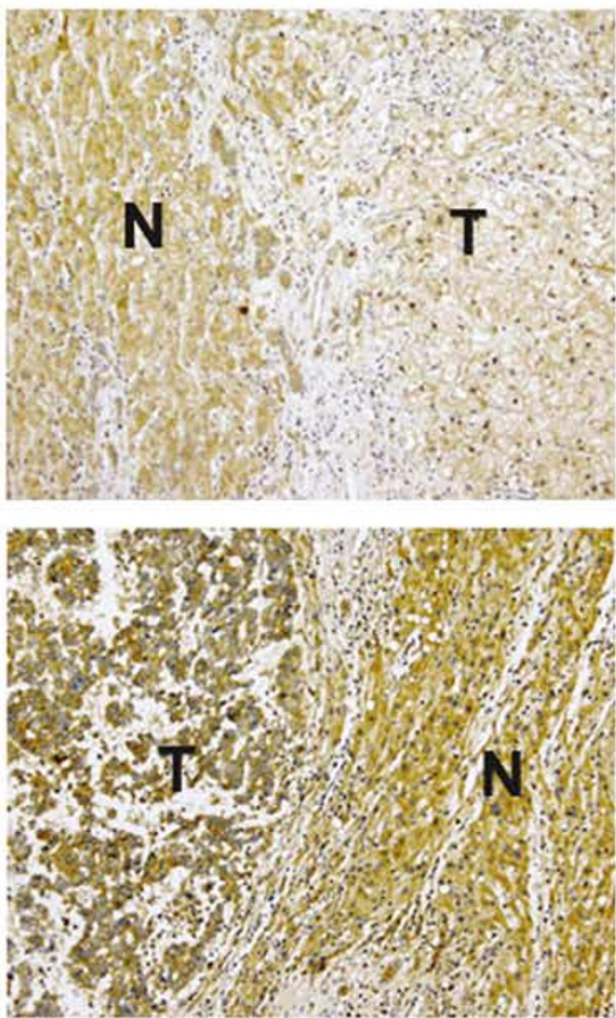

stage III

\section{stage IV}
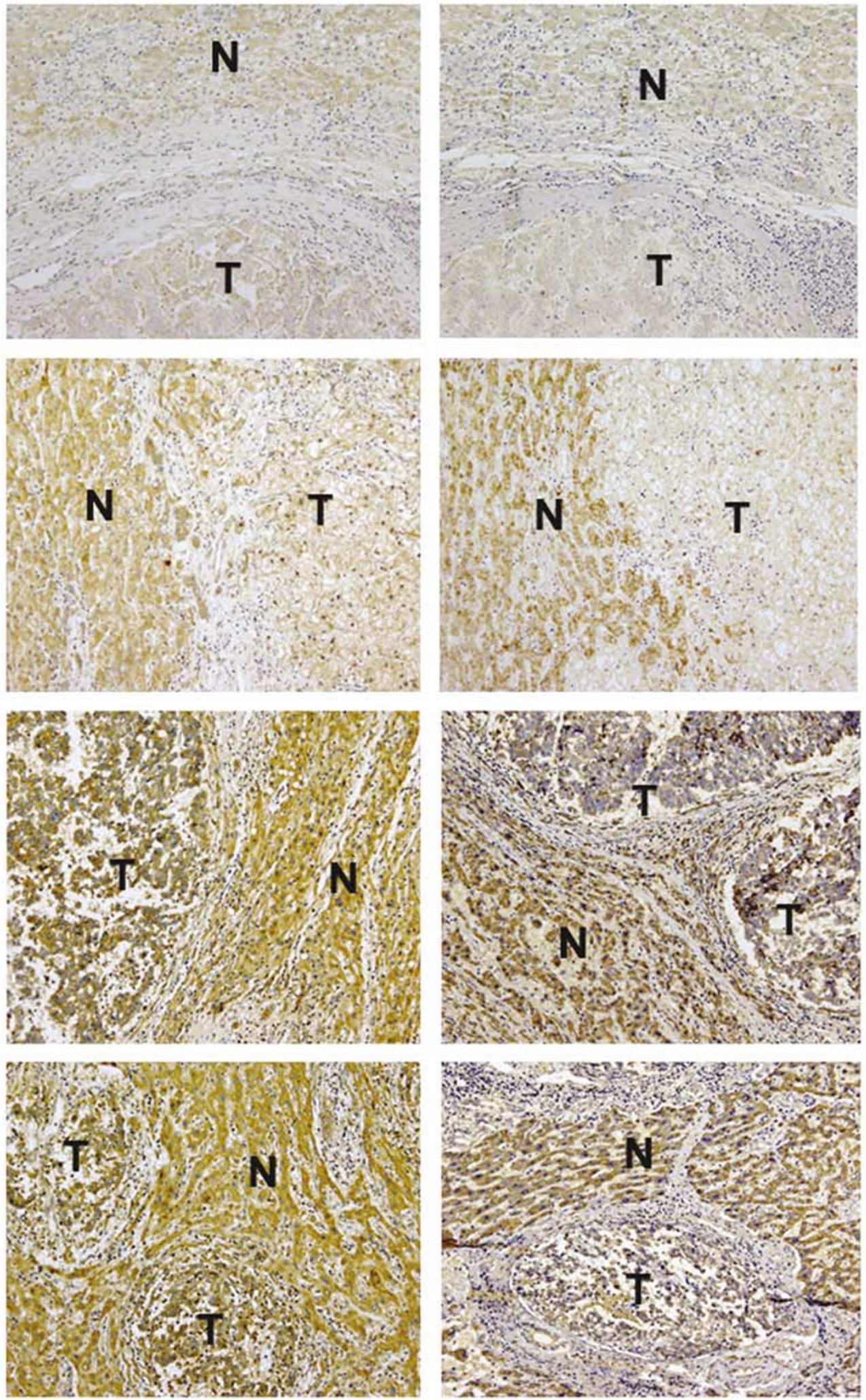

Figure 4 The correlation between endostatin/C18 and VEGF expression in HCC specimens. The profiles of C18 and VEGF expression were taken from HCC specimens of different stages (I-IV). The staining intensities of endostatin/C18 and VEGF were strong in advanced HCC (stages III and IV). Besides, there was a significant correlation between C18 and VEGF expression. The photographs were taken at an original magnification of $\times 200$.

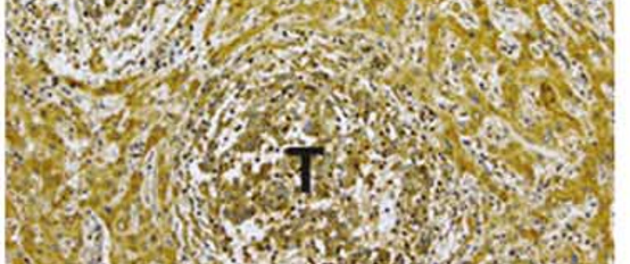

VEGF 
670
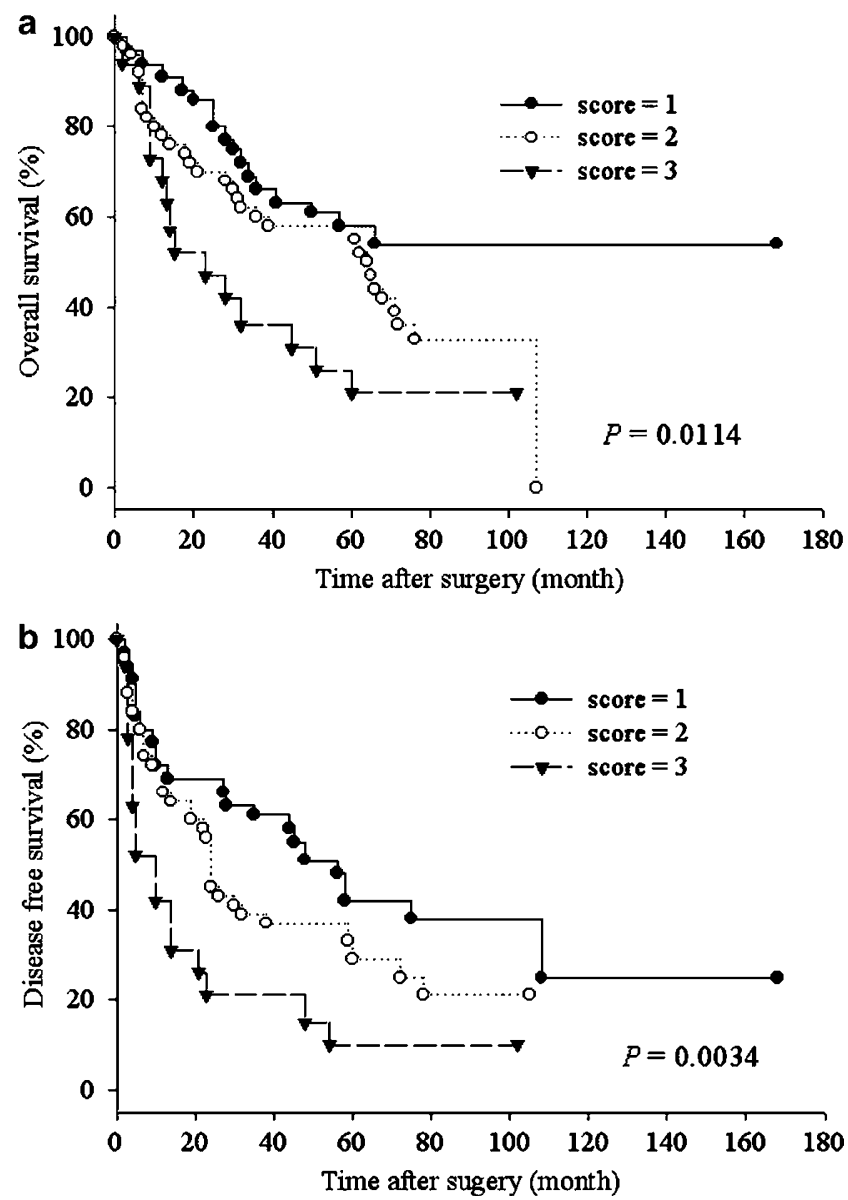

Figure 5 The prognostic value of tissue endostatin/C18 level in HCC patients after surgery. (a) The relationship between endostatin/C18 expression in nontumor tissues and overall survival. (b) The relationship between endostatin/C18 expression in nontumor tissues and disease-free survival of the HCC patients. The HCC patients were divided into three groups based on their endostatin/ C18 staining scores in nontumor tissues (score $=1,2$, and 3 for low, moderate, and high, respectively). The significance between endostatin/C18 in nontumor and survival outcome of patients after surgery was analyzed by Kaplan-Meier survival analysis. for tumor recurrence using univariate analysis (Table 2). After adjustment with other parameters, multivariate analysis revealed that only endostatin/ C18 level in nontumor tissues was an independent prognostic factor for disease-free survival of HCC patients $(P=0.034$; Table 2$)$.

\section{Discussion}

In the present study, we demonstrated for the first time that endostatin/C18 overexpression was associated with HCC progression from studies in hepatoma cell lines and clinical samples. Besides, in HCC specimens, the elevated endostatin/C18 level correlated with tumor stages (Table 1) and VEGF expression (Figure 4). Above all, the increased endostatin/C18 expression predicts poor survival outcome (Figure 5) and represents an independent prognostic factor for tumor recurrence after surgery (Table 2). These findings are consistent with recent observations of C18 upregulation in other types of cancer. ${ }^{20-22}$ Increased endostatin/C18 expression was found in the nontumor tissues of colorectal and ovarian cancers. ${ }^{20}$ Moreover, the tissue endostatin/C18 levels were higher in nontumor tissues and positively associated with malignancy grades in glioma ${ }^{21}$ and non-small-cell lung carcinoma. ${ }^{22}$ Thus, we herewith propose that increased endostatin/C18 may serve as a useful prognostic marker in patients with HCC.

In the present study, the specificity of endostatin antibodies was validated based on: (1) the distinct detection of endostatin and C18 derivatives in cell extracts of hepatoma cells (Figure 1) and (2) the immunoreactivities of endostatin antibodies to different types of liver cells (Figure 3) were consistent with previous studies. ${ }^{15,17,19}$ Given the high homology in endostatin domain (approximately $93 \%$ in amino acids sequences) between

Table 2 Univariate and multivariate analyses for disease-free survival of individual parameters

\begin{tabular}{|c|c|c|c|c|c|c|}
\hline & \multicolumn{3}{|c|}{ Univariate } & \multicolumn{3}{|c|}{ Multivariate } \\
\hline & Risk & $95 \% C I$ & $P$ & Risk & $95 \% C I$ & $\mathrm{P}$ \\
\hline C18 (non-tumor) & 1.68 & $1.21-2.35$ & $0.002^{*}$ & 1.45 & $1.03-2.04$ & $0.034^{*}$ \\
\hline C18 (tumor) & 1.46 & $1.06-2.02$ & $0.022^{*}$ & & & 0.142 \\
\hline Age & 0.73 & $0.45-1.18$ & 0.20 & & & \\
\hline Gender & 1.03 & $0.59-1.79$ & 0.93 & & & \\
\hline Hepatic fibrosis & 1.13 & $0.67-1.98$ & 0.35 & & & \\
\hline $\mathrm{HBV}+$ & 1.26 & $0.76-2.10$ & 0.37 & & & \\
\hline $\mathrm{HCV}+$ & 0.84 & $0.50-1.42$ & 0.52 & & & \\
\hline Grades & 1.48 & $1.06-2.05$ & $0.02 *$ & & & 0.151 \\
\hline Stages & 2.96 & $1.83-4.79$ & $<0.001^{*}$ & 3.96 & $2.31-6.79$ & $<0.001$ * \\
\hline Tumor size & 1.34 & $0.84-2.11$ & 0.22 & & & \\
\hline Tumor number & 1.60 & $0.96-2.66$ & 0.07 & & & \\
\hline$\alpha$-FP & 2.89 & $1.80-4.67$ & $<0.001^{*}$ & 3.12 & $1.91-54.10$ & $<0.001^{*}$ \\
\hline Capsulation & 4.76 & $0.29-0.77$ & $0.003^{*}$ & & & 0.288 \\
\hline
\end{tabular}

Age, $\geq 60$ or $<60$ years; gender, male or female; hepatic fibrosis, score 4 or $0-3$; HBV+, with or without; HCV+, with or without; grades, I+II or III+IV; stages, I+II or III+IV; tumor size, $\geq 5$ or $<5 \mathrm{~cm}$; tumor number, solitary or $\geq 2$; serum $\alpha$-FP, $\geq 700$ or $<700$; capsulation, with or without. ${ }^{*} P<0.05$. 
mouse and human $\mathrm{C} 18,{ }^{23}$ it seems plausible that antibodies against mouse endostatin detected human endostatin and C18 with high specificity as presented in this study. However, we could not rule out the probable reactivities to other types of collagen in human tissues.

One major finding in this study was to identify the correlation between tissue endostatin/C18 and VEGF level during HCC progression. It may seem paradoxical because VEGF is known for its proangiogenesis function while endostatin is an angiogenesis inhibitor. However, cumulative evidences indicate that serum endostatin and VEGF level are concomitantly escalated in many types of cancer ${ }^{15,24-28}$ including HCC. ${ }^{15}$ Assuming the serum endostatin levels reflected that in tissues, the correlation between tissue endostatin/ C18 and VEGF level in HCC samples seemed to be consistent with such an observation. However, the mechanism underlying the upregulation between endostatin and VEGF is not clear. One possibility was that endostatin/C18 was upregulated to counteract the imbalance of angiogenic stimuli near the tumor blood vessels during HCC progression. Alternatively, VEGF and endostatin/C18 expression was regulated via an uncharacterized common pathway during HCC progression. Analysis of promoter region of $\mathrm{C} 18$ gene may assist in shedding light on the C18 gene regulation. Recent evidences suggested that endostatin/ C18 may promote, instead of abolish, angiogenic processes..$^{29-31}$ Free, soluble endostatin was demonstrated to inhibit angiogenesis, whereas immobilized form of endostatin supports the survival and migration of endothelial cells. ${ }^{29,30}$ Besides, studies on C18-null mice indicated that C18 is essential for angiogenesis in the eyes. ${ }^{31}$ Given the complexity of endostatin production and function, future studies are warranted to delineate the mechanism underlying endostatin/C18 upregulation during HCC progression.

The role of endostatin/C18 expression during liver fibrosis was controversial. C18 levels were first reported to correlate with cirrhosis in HCC specimens. ${ }^{12}$ Moreover, in rat models of fibrogenesis, C18 expression is upregulated in chronic biliary fibrosis, but remains constant in acute fibrogenesis. ${ }^{32}$ However, RNA array analysis did not support the correlation between endostatin/C18 levels and cirrhosis status in HCC. ${ }^{14}$ In the present study, immunohistochemical studies indicated that endostatin/C18 levels in tumor or nontumor tissues were not relevant to the hepatic fibrosis stages in HCC tissues (Table 1). Furthermore, qRT-PCR analysis of RNA from cirrhotic tissues failed to identify significant correlation between endostatin/C18 expression and liver cirrhosis (data not shown). In summary, increased endostatin/C18 expression is associated with advanced stages and poor prognosis in HCC patients, but not related to liver fibrosis.

\section{Acknowledgements}

This work was supported in part by grants from the National Science Council, Taiwan (NSC-892315-B-182A-005 to T-HH, NSC-90-2320-B-075B018 to MHT), Kaohsiung Veterans General Hospital (VGHKS-90-17 and VGHUST-G3-03-3), and Chang Gung Memorial Hospital (CMRP-1130).

\section{References}

1 An FQ, Matsuda M, Fujii $\mathrm{H}$, et al. Expression of vascular endothelial growth factor in surgical specimens of hepatocellular carcinoma. J Cancer Res Clin Oncol 2000;126:153-160.

2 Li XM, Tang ZY, Zhou G, et al. Significance of vascular endothelial growth factor mRNA expression in invasion and metastasis of hepatocellular carcinoma. J Exp Clin Cancer Res 1998;17:13-17.

3 El-Assal ON, Yamanoi A, Soda Y, et al. Clinical significance of microvessel density and vascular endothelial growth factor expression in hepatocellular carcinoma and surrounding liver: possible involvement of vascular endothelial growth factor in the angiogenesis of cirrhotic liver. Hepatology 1998;27: 1554-1562.

4 Lee GH, Merlino G, Fausto N. Development of liver tumors in transforming growth factor alpha transgenic mice. Cancer Res 1992;52:5162-5170.

5 Rogler CE, Yang D, Rossetti L, et al. Altered body composition and increased frequency of diverse malignancies in insulin-like growth factor-II transgenic mice. J Biol Chem 1994;269:13779-13784.

6 Ueki T, Fujimoto J, Suzuki T, et al. Expression of hepatocyte growth factor and its receptor c-met protooncogene in hepatocellular carcinoma. Hepatology 1997;25:862-866.

7 Good DJ, Polverini PJ, Rastinejad F, et al. A tumor suppressor-dependent inhibitor of angiogenesis is immunologically and functionally indistinguishable from a fragment of thrombospondin. Proc Natl Acad Sci USA 1990;87:6624-6628.

8 O’Reilly MS, Holmgren L, Shing Y, et al. Angiostatin: a novel angiogenesis inhibitor that mediates the suppression of metastases by a Lewis lung carcinoma. Cell 1994;79:315-328.

9 O’Reilly MS, Boehm T, Shing Y, et al. Endostatin: an endogenous inhibitor of angiogenesis and tumor growth. Cell 1997;88:277-285.

10 Boehm T, Folkman J, Browder T, et al. Antiangiogenic therapy of experimental cancer does not induce acquired drug resistance. Nature 1997;390:404-407.

11 Kerbel RS. A cancer therapy resistant to resistance. Nature 1997;390:335-336.

12 Schuppan D, Cramer T, Bauer M, et al. Hepatocytes as a source of collagen type XVIII endostatin. Lancet 1998;352:879-880.

13 Yamagata M, Shiratori Y, Dan Y, et al. Serum endostatin levels in patients with hepatocellular carcinoma. Ann Oncol 2000;11:761-762.

14 Musso O, Rehn M, Theret N, et al. Tumor progression is associated with a significant decrease in the expression of the endostatin precursor collagen XVIII in human hepatocellular carcinomas. Cancer Res 2001;61:45-49. 
15 Dhar DK, Ono T, Yamanoi A, et al. Serum endostatin predicts tumor vascularity in hepatocellular carcinoma. Cancer 2002;95:2188-2195.

16 Chau YP, Lin SY, Chen JH, et al. Endostatin induces autophagic cell death in EAhy926 human endothelial cells. Histol Histopathol 2003;18:715-726.

17 Miosge N, Sasaki T, Timpl R. Angiogenesis inhibitor endostatin is a distinct component of elastic fibers in vessel walls. FASEB J 1999;13:1743-1750.

$18 \mathrm{Hu} \mathrm{TH}$, Huang CC, Lin PR, et al. Expression and prognostic role of tumor suppressor gene PTEN/ MMAC1/TEP1 in hepatocellular carcinoma. Cancer 2003;97:1929-1940.

19 Muragaki Y, Timmons S, Griffith CM, et al. Mouse Col18a1 is expressed in a tissue-specific manner as three alternative variants and is localized in basement membrane zones. Proc Natl Acad Sci USA 1995;92: 8763-8767.

20 Guenther U, Herbst H, Bauer M, et al. Collagen type XVIII/endostatin is differentially expressed in primary and metastatic colorectal cancers and ovarian carcinomas. Br J Cancer 2001;85:1540-1545.

21 Morimoto T, Aoyagi M, Tamaki M, et al. Increased levels of tissue endostatin in human malignant gliomas. Clin Cancer Res 2002;8:2933-2938.

22 Chang $\mathrm{H}$, Iizasa $\mathrm{T}$, Shibuya $\mathrm{K}$, et al. Increased expression of collagen XVIII and its prognostic value in nonsmall cell lung carcinoma. Cancer 2004;100: 1665-1672.

23 Saarela J, Ylikarppa R, Rehn M, et al. Complete primary structure of two variant forms of human type XVIII collagen and tissue-specific differences in the expression of the corresponding transcripts. Matrix Biol 1998;16:319-328.
24 Homer JJ, Greenman J, Stafford ND. Angiogenic cytokines in serum and plasma of patients with head and neck squamous cell carcimona. Clin Otolaryngol 2000;25:570-576.

25 Feldman AL, Tamarkin L, Paciotti GF, et al. Serum endostatin levels are elevated and correlate with serum vascular endothelial growth factor levels in patients with stage IV clear cell renal cancer. Clin Cancer Res 2000;6:4628-4634.

26 Feldman AL, Pak H, Yang JC. Serum endostatin levels are elevated in patients with soft tissue sarcoma. Cancer 2001;91:1525-1529.

27 Feldman AL, Alexander Jr HR, Bartlett DL, et al. A prospective analysis of plasma endostatin levels in colorectal cancer patients with liver metastases. Ann Surg Oncol 2001;8:741-745.

28 Feldman AL, Alexander Jr HR, Yang JC, et al. Prospective analysis of circulating endostatin levels in patients with renal cell carcinoma. Cancer 2002;95: 1637-1643.

29 Dixelius J, Larsson H, Sasaki T, et al. Endostatininduced tyrosine kinase signaling through the Shb adaptor protein regulates endothelial cell apoptosis. Blood 2000;95:3403-3411.

30 Rehn M, Veikkola T, Kukk-Valdre E, et al. Interaction of endostatin with integrins implicated in angiogenesis. Proc Natl Acad Sci USA 2001;98:1024-1029.

31 Fukai N, Eklund L, Marneros AG, et al. Lack of collagen XVIII/endostatin results in eye abnormalities. EMBO J 2002;21:1535-1544.

32 Jia JD, Bauer M, Sedlaczek N, et al. Modulation of collagen XVIII/endostatin expression in lobular and biliary rat liver fibrogenesis. J Hepatol 2001;35: 386-391. 